\title{
AN ANALYTICAL APPROACH OF SOURCES OF CONFLICT AMONG STUDENTS
}

\author{
Luiza Enachi-Vasluianu, ${ }^{1}$ Flavia Mălureanu ${ }^{2}$
}

\begin{abstract}
In a broad sense, conflict is an interactive process displayed through incompatibility, disagreement or dissension among social entities such as individuals, groups, organizations, etc. In a society in a changing, based on competitiveness, conflict is an integral part of human relationships, as it is a natural component of everyday life. New perspectives on conflict agree that its presence is natural and inherent in the human activity. The educational context is, inevitably, a space of conflicts. According to the actors involved, there has been established the following typology of conflicts: (a) conflicts among students, (b) conflicts among students and teachers, (c) conflicts among teachers and parents, and (d) conflicts among teachers. This paper aims to study the sources of conflict between students at the gymnasium and high school levels to lay emphasis on the aspects that could generate situations of risk or even educational crisis. The starting point in the research was specific literature, the observations and the experiences in the classroom. The items identified were a competitive atmosphere, intolerance, deficient communication as a result of linguistic ambiguity, inappropriate expressions of emotions, aggressiveness, lack of skills in solving conflicts, abuse of teacher's authority, etc. A questionnaire-based survey was developed, and the respondents were instructed to answer depending on how often they met the situations described by the indicators in the questionnaire. The results obtained were processed using the SPSS analysis. Further studies on conflicts between teachers and students/parents, teachers/peers can complete the research.
\end{abstract}

UDC Classification: 373; DOI: http://dx.doi.org/10.12955/cbup.v5.992

Keywords: conflict, sources of conflict, school tensions, competitiveness

\section{Introduction}

Conflict in education has been under scrutiny in the recent years. Perceived as a significant feature of human development, conflict represents the quintessence and the premise of the personal and social change. Inherently, the school space is conflictual, with tensions in several aspects such as knowledge, social and political. Current studies of pedagogy have classified conflict in school according to various and multiple criteria. Our paper will limit the research to the analyses of some selected sources of conflict among students belonging to two different school levels, taking into consideration the specifics of the present Romanian educational context.

\section{Literature review}

Competition in education is a tough fight, most of the times, irrelevant, for a place in the top of the school hierarchy. Traditionally, teachers consider that competition is efficient as a source of increasing motivation for learning. However, this competitive system generates the marginalization of students with low intellectual skills, even if these students are skilled in other different fields, such as art, sports, etc. The competition becomes destructive only when it is exaggerated and becomes a goal. In this case, it cancels cooperation (Bocoș et al., 2008) and may generate conflicts and aggressive behaviors within the group (Neculau, 1996) as it creates rivalries, envy, selfishness, etc.

The type of relationship among the students of a classroom, as well as the quality of interpersonal communication, depending upon the attitudes of each of the agents involved (Abric, 2002). Intolerance is about hostility, negative judgment, superior attitude, negative feedback. Intolerance is present in all aspects of society, ethnic, racial, cultural, economic, educational. The inequalities within the groups, in which people are exposed to discrimination, marginalization as manifestations of intolerance can lead to conflicts or even exclusion (Nedelcu, 2007). As such, students must learn to accept one another, to develop tolerant attitudes and behaviors because they often get to conflicts as they are convinced that the others do not accept or like them (Olsen, Nielsen, 2009).

The way emotions are expressed significant for social interactions as it contributes to their maintenance or degradation and triggers the appearance of conflicts (Sălăvăstru, 2004). Children's inadequate expression of negative emotions (fury, fear, sadness) through physical or verbal aggression determines the appearance of similar behavior or isolation. Children who behave aggressively have difficulties in recognizing and understanding the emotions expressed by the others in a given situation, thus initiating conflicts. On the other hand, some children express their emotions through exaggerated

\footnotetext{
${ }^{1}$ Faculty of Psychology and Educational Sciences, University of Bucharest, Romania, vasluianu_luiza@yahoo.com

${ }^{2}$ Faculty of Psychology and Educational Sciences, University of Bucharest, Romania, flaviamalureanu@ yahoo.com
} 
manifestations such as outpouring laughter, ample, theatrical gestures or physical aggressiveness when they like somebody so as to draw attention to themselves, etc. As children grow up, their emotional expression is affected by cultural values, gender stereotypes, etc.

Ambiguity in communication is based on insufficient, untrue information, inadequate channels of communication or lack of open communication among colleagues (Bocoș et al., 2008). Alongside these, research demonstrated that ambiguity in communication is also triggered by linguistic elements such as polysemy, intensifiers of negation, modality, indefiniteness, anaphora, modifiers, gradability, figures of speech (Mălureanu, Enachi-Vasluianu, 2015). Children have a tendency to make extensive use of such linguistic elements and, sometimes, their inappropriate or erroneous use may lead to misunderstandings which develop into conflicts.

Children aged 11-18 lack abilities to solve conflicts. They may know some of the strategies described in the specialized literature, compromise, retreat of one of the conflictual sides, consensus, negotiation, mediation (Păun, 1999), but they do not possess the necessary experience, tact or will to put them into practice, especially in the case of gymnasium children. As a matter of fact, with gymnasium children, the use of hierarchic authority (teacher, parent, elder brothers) leads to conflict attenuation or even elimination. With high school students, there is a tendency to avoid outside involvement and try to solve different conflicts by themselves.

Reboul (1971) states authority indicates the supremacy of the one that practices it, so it establishes a vertical relationship. The authoritative teacher can impose certain decisions that may be contrary to students' desires, may favor some students in others' detriment, may discriminate students with low results through criticism, may evaluate students in negative terms, may humiliate publically. Some students may easily assume these behaviors to obtain supremacy in front of their colleagues, which may determine significant interpersonal tensions. The relationships between the groups led authoritatively evolve from great interpersonal tensions, manifestations of irritability and hostility towards team colleagues to the collective aggressiveness of more subjects against one of them who becomes an "escape goat" (Sălăvăstru, 2004).

Specialists in social psychology state that aggressiveness is the tendency to answer hostilely to unpleasant interactions. Aggressive children can orientate their aggressiveness on a colleague by hitting, insulting, mocking him or indirectly by speaking ill behind his back or laying traps for him (Eibl-Eibesfeldt, 1995). On the other hand, the students included in our study talked about another form of aggressiveness, stubbornness identified as passive aggressiveness, defined as refusal to do what is necessary or what is requested. The two ways of aggressiveness, active and passive, create pressure, a tension which may eventually lead to conflicts.

\section{Methodology of Research}

\section{Objectives}

The research objectives are a) to identify the sources of conflict among students at gymnasium and high school levels in order to lay emphasis on the aspects that could generate situations of risk or even educational crisis, b) to realize descriptive analyses of the selected elements to determine a hierarchy of two school levels, gymnasium and high school.

\section{Participants}

The sample used for research was made of 100 students from Vrancea County, Romania, split evenly in number: 50 from gymnasium students (ages 11-14) and 50 high schools (ages 14-18). The students volunteered to take part in the research.

\section{Research instrument}

The main method used in our research was the questionnaire-based investigation. The questionnaire was built based on specific literature and focus-group discussions with students from the two school levels. This method allowed the identification of a series of sources of conflict among students transposed into the following items: competitive atmosphere, intolerance, deficient communication as a result of linguistic ambiguity, inappropriate expressions of emotions, aggressiveness, lack of skills in solving conflicts, abuse of teacher's authority that can generate into envy. 
The respondents chose one of the following variants of a five-step scale: (1) to a very low extent, (2) to a low extent, (3) to an average extent, (4) to a large extent, (5) to a very large extent. These steps are showing the relevance of each item as a source of conflict.

\section{Results and Discussion}

For the descriptive analyses, we used SPSS software, the t-test for the independent samples.

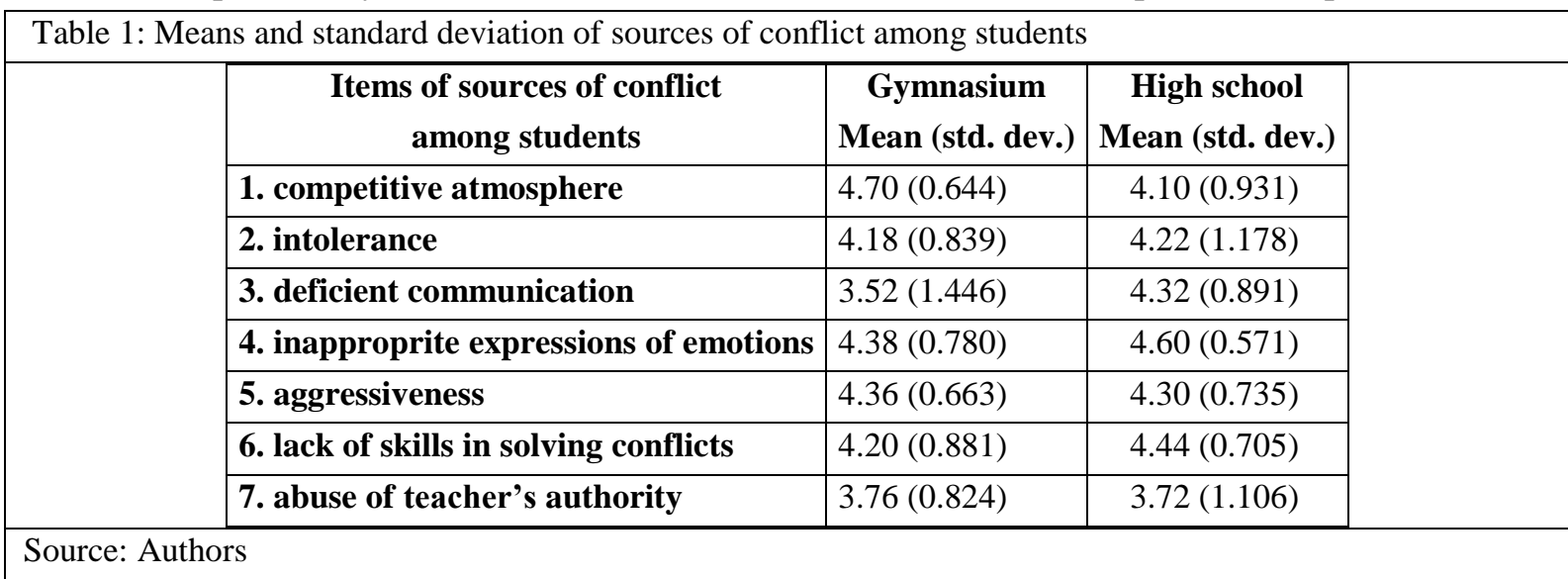

The means in Table 1 were used to realize a hierarchy of sources of conflict among students for the two school levels. Thus, the indicator ranked one was considered the source with major impact in triggering conflicts, whereas the indicator ranked seven was less appreciated as a source of conflict among students.

\begin{tabular}{|l|l|l|l|}
\hline \multicolumn{2}{|c|}{ Table 2: Description of hierarchy of sources of conflict among students } \\
\hline \multicolumn{1}{|c|}{ Rank } & \multicolumn{1}{|c|}{ Gymnasium } & High school \\
\cline { 2 - 4 } & $\mathbf{1 .}$ & competitive atmosphere & inappropriate expressions of emotions \\
\hline $\mathbf{2 .}$ & inappropriate expressions of emotions & lack of skills in solving conflicts \\
\hline $\mathbf{3 .}$ & aggressiveness & deficient communication \\
\hline $\mathbf{4 .}$ & lack of skills in solving conflicts & aggressiveness \\
\hline $\mathbf{5 .}$ & intolerance & intolerance \\
\hline $\mathbf{6 .}$ & abuse of teacher's authority & competitive atmosphere \\
\hline $\mathbf{7 .}$ & deficient communication & abuse of teacher's authority \\
\hline
\end{tabular}

According to the hierarchy resulted from the investigation, competitive atmosphere $(\mathrm{m}=4.70)$ registered the highest means for gymnasium students, while inappropriate use of emotions $(\mathrm{m}=4.60)$ rated highest for high school students. Placing competitive atmosphere as the main source of conflict for gymnasium students is explained on the one hand, through the importance of the final grade for all four gymnasium years, as it represents a certain percentage of high school entrance grades. On the other hand, students declared in focus-group discussions that the competitive atmosphere is supported by teachers who encourage this form of educational progress. As for the inappropriate use of emotions with high school students, the age of adolescence is characterized through emotional exaltation which may lead to the amplification, the exaggeration of emotional-expressive behaviors (Crețu, 2005). Deficient communication $(\mathrm{m}=3.52)$ for gymnasium students and abuse of teacher's authority $(\mathrm{m}=$ 3.72) for high school students registered the lowest means.

Gymnasium responses registered means above 4 for five items: competitive atmosphere $(\mathrm{m}=4.70)$, inappropriate expressions of emotions $(\mathrm{m}=4.38)$, aggressiveness $(\mathrm{m}=4.36)$, lack of skills in solving conflicts $(\mathrm{m}=4.20)$, intolerance $(\mathrm{m}=4.18)$. High school responses registered means above 4 for six items: inappropriate expressions of emotions $(\mathrm{m}=4.60)$, lack of skills in solving conflicts $(\mathrm{m}=4.44)$, 
deficient communication as a result of linguistic ambiguity $(\mathrm{m}=4.32)$, aggressiveness $(\mathrm{m}=4.30)$, intolerance $(\mathrm{m}=4.22)$, competitive atmosphere $(\mathrm{m}=4.10)$. These means show that students in both school levels consider these items as sources with major impact in triggering conflicts. Even the lowest means are above 3.5, which demonstrate the importance students pay to these items as significant sources of conflict among students.

The $\mathrm{T}$ test was used for the independent groups to determine the differences of the opinions regarding the sources of conflict among students. The significance level was set to 0.05 . Starting from the significant differences from a statistical point of view among students' appreciations, we could state the relevance of the sources of conflict. Thus, the analysis of the appreciations of the students from the gymnasium and high school brought to significant light differences for two items (deficient communication and competitive atmosphere, $\mathrm{p}<0.05)$. The divergence of opinions regarding the two elements is reflected on the hierarchy in Table 2. Thus, deficient communication ranked $7(\mathrm{~m}=3.52)$ at gymnasium level and $3(\mathrm{~m}=4.32)$ at high school level. The comparative analysis of the two means shows higher appreciation with high school responses. This demonstrates that deficient communication has a greater relevance as a source of conflict for high school students. The second item which registered statistically significant differences is a competitive atmosphere. According to Table 2, it ranked $1(\mathrm{~m}=4.70)$ at gymnasium level and $6(\mathrm{~m}=4.10)$ at high school level. The higher mean is registered with the gymnasium responses. Statistically insignificant differences were registered for five items, indicating convergence of opinions of the students from the two school levels.

\section{Conclusion}

Although conflicts are not desired in the educational communication, they exist. Specific literature underlines that a solved conflict may be seen as a source of learning, as previous experience for others to come and thus the participants will know how to react to diminish the impact of the phenomenon or even solve it. The existence of conflicts helps to discover personal values and beliefs, contributes to developing proper conflict management skills.

Our study demonstrated that students pay attention to conflict as an important issue in education by giving high scores to the sources identified in the research. We also appreciated their involvement in focus-groups discussions as they provided examples or drew attention upon different conflictual situations. The selection of the sources of conflict for this research was made according to the specifics of the present Romanian educational context. Although they were analyzed individually, the sources of conflict can act separately or in combinations determined by the situation in case. Mention must be made that there is a much richer range of sources of conflict that generate particular aspects, strategies of preventing and solving, which could be dwelled upon in further studies.

\section{References}

Abric, J.C. (2002). Psihologia comunicării. Iași: Polirom.

Bocoș, M., Gavra, R., \& Marcu, S. D. (2008). Comunicarea și managementul conflictului. Pitești: Paralela 45.

Crețu, T. (2005). Psihologia copilului. București: PIR, 41.

Eibl-Eibesfeldt, I. (1995). Agresivitatea umană. București: Trei.

Mălureanu, F., \& Enachi-Vasluianu, L. (2015). A Study on the Linguistic Elements of Vagueness in the Didactic Discourse. Retrieved from https://www.scribd.com/doc/286449807/Proceedings-of-ICVL-2015-ISSN-1844-8933-ISI-Proceedings

Neculau, A., (1996). Psihologie socială. Iași: Polirom.

Nedelcu, D. (2007). Educaţie democratică, incluziune și interculturalitate. București: Didactică şi Pedagogică, 10-12.

Olsen, J., \& Nielsen, T.W. (2009). Noi metode şi strategii pentru managementul clasei, București: Didactica Publishing House.

Păun, E. (1999). Şcoala - abordare sociopedagogică. Iaşi: Polirom.

Reboul, O. (1971). La Philosophie de l'education. Paris: PUF.

Sălăvăstru, D. (2004). Psihologia educaţiei. Iaşi: Polirom, 131-132. 